\title{
Molecular docking reveals the potential of aliskiren, dipyridamole, mopidamol, rosuvastatin, rolitetracycline and metamizole to inhibit COVID-19 virus main protease
}

\author{
Omar M. Aly \\ .Medicinal Chemistry Department, Faculty of Pharmacy, Minia University, Minia, 61519, Egypt \\ Corresponding author. Tel.: +201065607771. Fax: +2086-2369075 \\ E-mail address: omarsokkar@yahoo.com, omarsokkar@mu.edu.eg \\ Postal address: Medicinal Chemistry Department, Faculty of Pharmacy, Minia University, Minia, 61519, \\ Egypt.
}

\begin{abstract}
Drug repurposing is a fast way to rapidly discover a drug for clinical use. In such circumstances of the spreading of the highly contagious COVID-19, searching for already known drugs is a worldwide demand. In this study, many drugs were evaluated by molecular docking. Among the test compounds, aliskiren (the best), dipyridamole, mopidamol and rosuvastatin showed higher energies of binding than that of the co-crystallized ligand N3 with COVID-19 main protease $\mathrm{M}^{\mathrm{pro}}$. Rolitetracycline showed the best binding with the catalytic center of the protease enzyme through binding with CYS 145 and HIS 41. Metamizole showed about $86 \%$ of the binding energy of the ligand N3 while the protease inhibitor darunavir showed little bit lower binding energy than N3. These results are promising for using these drugs in the treatment and management of the spreading of COVID-19 virus. Also, it could stimulate clinical trials for the use of these drugs by systemic or inhalation route.
\end{abstract}

Keywords: Docking; Aliskiren; Dipyridamole; Mopidamole; Rosuvastatin; Metamizole; Rolitetracycline; Darunavir; N3, COVID-19; Protease

\section{Introduction}

COVID-19 virus is the causative agent of the 2019-2020 viral pneumonia outbreak that commenced in Wuhan [1-4]. Finding out known drug that inhibit the COVID-19 virus 
main protease $\left(\mathrm{M}^{\mathrm{pro}}\right)$ will result in a pivotal role in controlling viral replication and transcription [5,6]. Here, I selected the most promising drugs among my vast screenings to recommend them relying on the molecular docking results obtained in comparison with the ligand N3.<smiles>COCCCOc1cc(C[C@H](CC(N)C(O)C[C@@H](C(=O)NCC(C)(C)C(N)=O)C(C)C)C(C)C)ccc1OC</smiles><smiles>Cc1nc(N(C)S(C)(=O)=O)nc(-c2ccc(F)cc2)c1/C=C/C(O)C[C@@H](O)CC(=O)O</smiles><smiles>CC(C)CN(CC(O)[C@H](Cc1ccccc1)NC(=O)O[C@H]1CO[C@@H]2OCC[C@H]21)S(=O)(=O)c1ccc(N)cc1</smiles>

g<smiles></smiles>

Fig.1: Chemical structures of compounds: Aliskiren a, Dipyridamole b, mopidamol c, rosuvastatin $\mathbf{d}$, metamizole $\mathbf{e}$, rolitetracycline $\mathbf{f}$, darunavir $\mathbf{g}$, and N3 $\mathbf{h}$.

Zhenming Jin, et al, determined the crystal structure of COVID-19 virus $\mathrm{M}^{\text {pro }}$ in complex with this compound [7]. The functional polypeptides are released from the polyproteins by extensive proteolytic processing, predominantly by a 33.8-kDa main protease $\left(\mathrm{M}^{\text {pro }}\right)$, also referred to as the $3 \mathrm{C}$-like protease. $\mathrm{M}^{\text {pro }}$ digests the polyprotein at no less than 11 conserved sites, starting with the autolytic cleavage of this enzyme itself from pp1a and pp1ab [8]. The functional importance of $\mathbf{M}^{\text {pro }}$ in the viral life 
cycle, together with the absence of closely related homologues in humans, identify the $\mathrm{M}^{\mathrm{pro}}$ as an attractive target for antiviral drug design [9].

The novel coronavirus 2019 (2019-nCoV) uses the SARS-coronavirus receptor ACE2 and the cellular protease TMPRSS2 for entry into target cells [10].

Here, the most promising drugs were selected to recommend them for potential treatment of the new COVID-19 infection relying on the molecular docking results obtained in comparison with the ligand N3. Chemical structures of the compounds tested in this study are shown in Fig. 1. Aliskiren is an oral renin inhibitor that be used for the treatment of hypertension [11]. The reduced expression of ACE2 with aliskiren treatment could be an interesting option in the context of SARS-CoV-2 infection that requires further investigation [12]. Dipyridamole is platelet aggregation and a phosphodiesterase (PDE) inhibitor [13], also it showed broad spectrum antiviral activity [14-17]. Most importantly, dipyridamole may prevent acute injury and progressive fibrosis of the lung, heart, liver, and kidney associated with COVID 19 infection [18].

Mopidamol is a chemical congener (Fig. l) of dipyridamole, similarly, acts as a coronary vasodilator and platelet aggregation inhibitor. In addition, mopidamol has shown antimetastatic properties by inhibiting the adherence of cancer cells to platelets or endothelial cells. Although both compounds cause inhibition of CAMP phosphodiester but mopidamol is 10 times more potent than dipyridamole[19,20].

Rosuvastatin is a synthetic HMG-CoA reductase inhibitor that are effective in the reduction of total and LDL cholesterol [21].

While no clinical data yet exists for a protective role for statins for COVID-19 infection, there are some data that are suggestive that they may be associated with less severe viral pneumonia (perhaps for similar reasons described in point $\mathbf{C}$ ). A large matched cohort study found a reduced risk of COPD death and influenza death for patients on moderate dose statins compared to not [22].

Metamizole, or dipyrone, is a painkiller, spasm reliever, and fever reliever that also has anti-inflammatory effects. It is most commonly given by mouth or by injection. 
Although it is available over the counter in some countries, it is prescription or banned in other countries, due to its potential for adverse events, including agranulocytosis [23].

Rolitetracycline, launched in the late 1950s, was the first of the semi-synthetic tetracyclines. Rolitetracycline is formed by a Mannich condensation of formaldehyde and pyrrolidine with tetracycline. Rolitetracycline is a pro-drug of tetracycline, in which the pyrrolidine moiety improves bioavailability compared with tetracycline. Rolitetracycline has broad-spectrum Gram-positive activity in vivo, but $\mathrm{pH}$ instability limits use to parenteral administration [24].

Rolitetracycline is only found in individuals that have used or taken this drug. It is a pyrrolidinylmethyl tetracycline. Rolitetracycline is a semisynthetic broad-spectrum tetracycline antibiotic used especially for parenteral administration in cases requiring high concentrations or when oral administration is impractical. Rolitetracycline passively diffuses through porin channels in the bacterial membrane and reversibly binds to the $30 \mathrm{~S}$ ribosomal subunit, preventing binding of tRNA to the mRNAribosome complex, and thus interfering with protein synthesis [25]

Darunavir is a once-daily second-generation protease-inhibitor [26,27] that is administered with low-dose ritonavir and two nucleoside reverse transcriptase inhibitors (NRTI) for treatment of HIV infection [28].

Currently, targeted therapeutics and effective treatments remain very limited. Here, in order to rapidly discover lead compounds for clinical use. attempts were made to identify new drug leads that target the COVID-19 virus main protease $\left(\mathrm{M}^{\mathrm{pro}}\right)$. Here, computer-aided drug design was used to find out a known drug to be used as target for the clinical usefulness as COVID-19 inhibitor. The compounds shown in Fig. 1 were compared with the $\mathrm{M}^{\text {pro }}$ co-crystallized ligand N3.

\section{Results and discussion}

COVID-19 virus Mpro has a Cys-His catalytic dyad, and the substrate-binding site is located in a cleft between Domain I and II. N3 is fitted inside the substrate-binding pocket of COVID-19 virus $\mathrm{M}^{\text {pro }}$ showing asymmetric unit containing only one polypeptide. All compounds (a-f) showed nearly similar binding to N3. Results of interaction energies with $\mathrm{M}^{\text {pro }}$ are shown in Table 1. Molecular docking simulation of 
compound a-f into $\mathrm{M}^{\text {pro }}$ active site was done. They got stabilized at the N3-binding site of $\mathrm{M}^{\text {pro }}$ by variable several electrostatic bonds (Fig. 2-4).

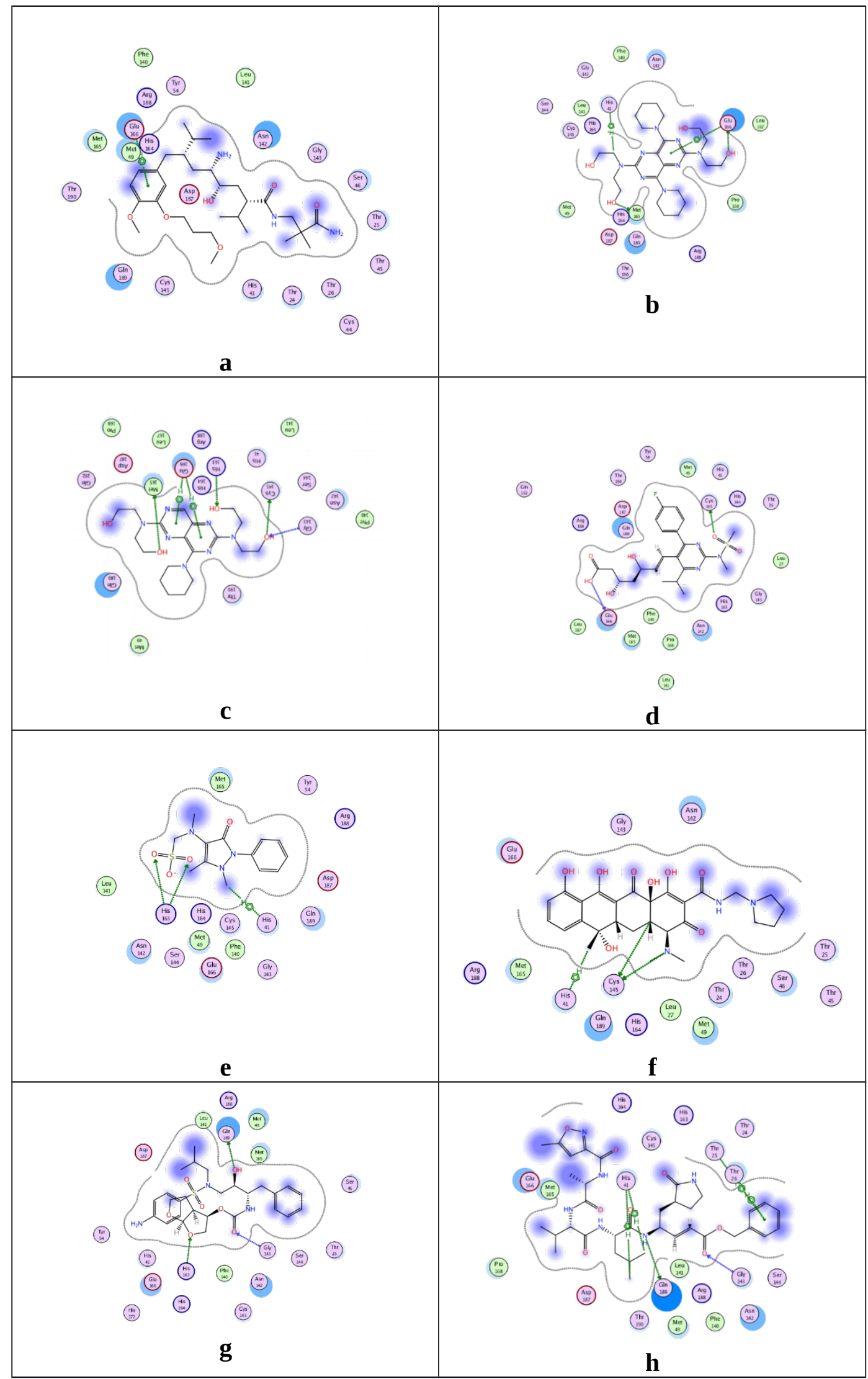


Fig. 2: 2D representation of docking of compounds: Aliskiren a, Dipyridamole $\mathbf{b}$, mopidamol c, rosuvastatin d, metamizole e, rolitetracycline f, darunavir $\mathbf{g}$, and N3 $\mathbf{h}$ into the N3 binding site in the COVID-19 protease.

Aliskiren was showed the highest binding energy in comparison with the other compounds which showed nearly equal or moderately lesser binding energies.

(n)




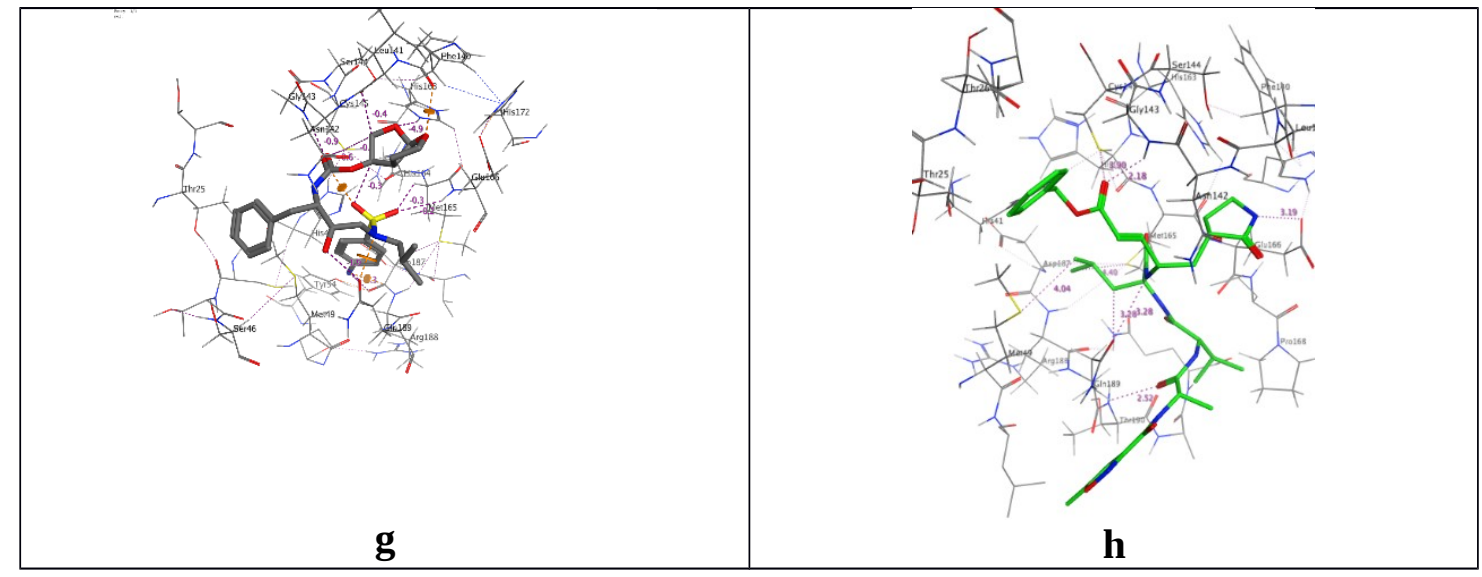

Fig. 3: 3D Docking poses of aliskiren a, dipyridamole b, mopidamol c, rosuvastatin d, metamizole $\mathbf{e}$, rolitetracycline $\mathbf{f}$, darunavir $\mathbf{g}$, and N3 $\mathbf{h}$ into the N3 binding site in the COVID-19 protease.

(2)




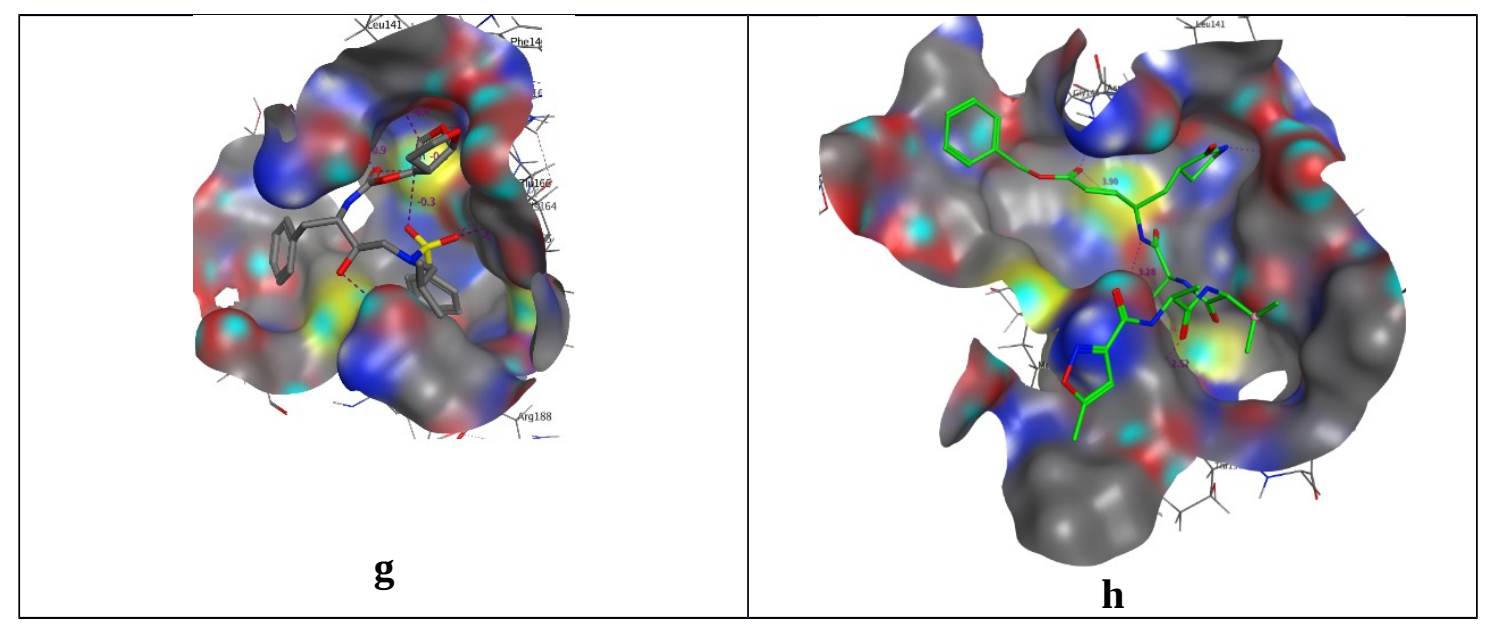

Fig. 4: Surface and maps of compounds aliskiren a, dipyridamole b, mopidamol c, rosuvastatin $\mathbf{d}$, metamizole $\mathbf{e}$, rolitetracycline $\mathbf{f}$, darunavir $\mathbf{g}$, and N3 $\mathbf{h}$ into the N3 binding site in the COVID-19 protease.

\section{Docking studies}

\section{Target compounds optimization}

The target compounds were constructed into a 3D model. After checking their structures and the formal charges on atoms by 2D depiction, the following steps were carried out: The target compounds were subjected to a conformational search. All conformers were subjected to energy minimization, all the minimizations were performed until a RMSD gradient of $0.01 \mathrm{Kcal} / \mathrm{mole}$ and RMS distance of $0.1 \AA$ with MMFF94X force-field and the partial charges were automatically calculated. The obtained database was then saved as MDB file to be used in the docking calculations.

\section{Optimization of the enzymes active site}

The X-ray crystallographic structure of $\mathrm{M}^{\text {pro }}$ complexed with N3 was obtained from the Protein Data Bank through the internet (http://www. rcsb.org/, PDB code 6LU7) [7]. The enzyme was prepared for docking studies by: Hydrogen atoms were added to the system with their standard geometry. The atoms connection and type were checked for any errors with automatic correction. Selection of the receptor and its atoms potential were fixed. Site Finder was used for the active site search in the enzyme structure using all default items. Dummy atoms were created from the site finder of the pocket.

\section{Docking of the target molecules to tubulin protein in colchicine binding site}


Docking of the conformation database of the target compounds was done. The following methodology was generally applied: The enzyme active site file was loaded, and the Dock tool was initiated. The program specifications were adjusted to: Dummy atoms as the docking site, alpha triangle as the placement methodology to be used. London dG as scoring methodology to be used and was adjusted to its default values. The MDB file of the ligand to be docked was loaded and Dock calculations were run automatically. The obtained poses were studied, and the poses showed best ligandenzyme interactions were selected and stored for energy calculations.

Table 1: Receptor interaction with aliskiren a, dipyridamole b, mopidamol c, rosuvastatin $\mathbf{d}$, metamizole $\mathbf{e}$, rolitetracycline $\mathbf{f}$, darunavir $\mathbf{g}$, and N3 $\mathbf{h}$ into the N3 binding site in the COVID-19 protease

\begin{tabular}{|c|c|c|c|c|}
\hline \multirow[b]{2}{*}{ Compound. } & \multirow[b]{2}{*}{$\begin{array}{c}\text { dG } \\
\text { Kcal/mol } \\
\text { e }\end{array}$} & \multicolumn{3}{|c|}{ Receptor Interaction } \\
\hline & & Amino acid/ Bond & $\begin{array}{c}\text { Distance } \\
\AA\end{array}$ & $\begin{array}{c}E \\
\text { Kcal/mole }\end{array}$ \\
\hline Aliskiren & -8.4965 & GLU 166 (A)/ pi-H & 4.50 & -0.8 \\
\hline Dipyridamole & -8.1152 & $\begin{array}{l}\text { GLU } 166 \text { (A)/ H-donor } \\
\text { MET } 165 \text { (A) / H-donor } \\
\text { HIS } 41 \text { (A) / H-pi } \\
\text { GLU } 166 \text { (A) /pi-H }\end{array}$ & $\begin{array}{l}3.21 \\
3.71 \\
4.21 \\
3.96\end{array}$ & $\begin{array}{l}-1.8 \\
-0.9 \\
-0.6 \\
-1.0\end{array}$ \\
\hline Mopidamole & -7.7676 & $\begin{array}{l}\text { MET } 165 \text { (A)/ H-donor } \\
\text { CYS } 145 \text { (A)/ H-donor } \\
\text { GLY143 (A)/ H- } \\
\text { Acceptor } \\
\text { HIS } 163 \text { (A)/ H- } \\
\text { acceptor } \\
\text { GLU } 166 \text { (A)/ pi-H } \\
\text { GLU } 166 \text { (A)/ pi-H }\end{array}$ & $\begin{array}{l}3.24 \\
3.40 \\
3.06 \\
3.43 \\
4.31 \\
4.28\end{array}$ & $\begin{array}{l}-1.2 \\
-1.6 \\
-2.3 \\
-0.6 \\
-0.8 \\
-0.9\end{array}$ \\
\hline Rosuvastatin & -7.7865 & $\begin{array}{l}\text { GLU } 166 \text { (A)/ H-donor } \\
\text { CYS } 145 \text { (A)/ H-donor }\end{array}$ & $\begin{array}{l}2.85 \\
3.13\end{array}$ & $\begin{array}{l}-3.9 \\
-1.3\end{array}$ \\
\hline Metamizole & -6.5052 & $\begin{array}{l}\text { HIS163(A)/H-acceptor } \\
\text { HIS163(A)/H-acceptor } \\
\text { HIS163(A)/ ionic } \\
\text { HIS163(A) / ionic } \\
\text { HIS 41 (A)/ H-pi }\end{array}$ & $\begin{array}{l}3.07 \\
3.40 \\
3.07 \\
3.40 \\
4.68\end{array}$ & $\begin{array}{l}-2.5 \\
-3.4 \\
-4.0 \\
-2.3 \\
-0.8\end{array}$ \\
\hline $\begin{array}{c}\text { Rolitetracyclin } \\
\text { e }\end{array}$ & -7.1222 & $\begin{array}{c}\text { CYS } 145 \text { (A) H-donor } \\
\text { CYS145(A)/H-donor } \\
\text { HIS } 41(\mathrm{~A}) / \mathrm{H}-\mathrm{pi} \\
\text { HIS } 41(\mathrm{~A}) / \mathrm{H}-\mathrm{pi}\end{array}$ & $\begin{array}{l}4.05 \\
3.92 \\
3.73\end{array}$ & $\begin{array}{l}-0.7 \\
-0.9 \\
-0.6\end{array}$ \\
\hline
\end{tabular}




\begin{tabular}{|l|l|l|l|l|}
\hline N3 & -7.7716 & GLN 189 (A) / H-donor & 3.26 & -3.1 \\
& & GLY 143 (A)/ H- & 3.04 & -1.2 \\
& & acceptor & 3.89 & -0.6 \\
& & HIS 41 (A)/ H-pi & 4.28 & -0.6 \\
& & HIS 41 (A)/ H-pi & 4.92 & -0.6 \\
& & THR 25 (A)/ pi-H & 4.43 & -1.1 \\
& & & \\
\hline
\end{tabular}

\section{Conclusion}

The molecular modeling of the selected compounds a-f resulted in the discovery of already approved drugs of potential potent activity to be repurposed as COVID-19 protease inhibitors. This will stimulate the evaluation of these drugs as anti COVID-19 especially aliskiren which showed the highest score of binding with the binding site of N3. This will be added to its renin inhibition and advantage of renin inhibition and possibility of the reduced expression of ACE2[12]. Dipyridamole and mopidamol showed a potential to be more $\mathrm{M}^{\text {pro }}$ inhibitor than ligand $\mathrm{N} 3$ and darunavir. Also, dipyridamole has the property of antiviral activity beside its use to decrease the hypercoagulabilty that happens due to COVID infection in addition to the property of promoting type I interferon (IFN) responses and protect mice from viral pneumonia [30]. Rolitetracycling is an amazing in its binding mode in the active site of the protease pocket it seemed as it is tailored to be buried in that pocket. Mopidamol and rosuvastatin are slightly better than the co-crystallized ligand N3 and darunavir in binding mode which nominate the as COVID-19 protease inhibitors. Hopefully this study will help in the repurposing a drug for the treatment of COVID-19.

\section{References:}

[1] Zhu, N. et al. A novel coronavirus from patients with pneumonia in China, 2019. New England Journal of Medicine (2020).

[2] Qun Li et al. Early Transmission Dynamics in Wuhan, China, of Novel Coronavirus-Infected Pneumonia. New England Journal of Medicine (2020).

[3] Zhou, P. et al. A pneumonia outbreak associated with a new coronavirus of probable bat origin.220 Nature, doi:10.1038/s41586-020-2012-7 (2020). 
[4] Wu, F. et al. A new coronavirus associated with human respiratory disease in China. Nature, 222 doi:10.1038/s41586-020-2008-3 (2020).

[5] Anand, K. et al. Structure of coronavirus main proteinase reveals combination of a chymotrypsin fold with an extra $\alpha$-helical domain. The EMBO Journal 21, 3213-3224 (2002).

[6] Yang, H. T. et al. The crystal structures of severe acute respiratory syndrome virus main protease and its complex with an inhibitor. Proceedings of the National Academy of Sciences of the United States of America 100, 13190-13195, doi:10.1073/pnas.1835675100 (2003).

[7] Zhenming Jin, et al, Structure of $\mathrm{M}^{\text {pro }}$ from COVID-19 virus and discovery of its inhibitors bioRxiv preprint doi: https://doi.org/10.1101/2020.02.26.964882

[8] Hegyi, A. \& Ziebuhr, J. Conservation of substrate specificities among coronavirus main proteases. Journal of general virology 83, 595-599 (2002).

[9] Pillaiyar, T., Manickam, M., Namasivayam, V., Hayashi, Y. \& Jung, S. H. An Overview of Severe Acute Respiratory Syndrome-Coronavirus (SARS-CoV) 3CL Protease Inhibitors: Peptidomimetics and Small Molecule Chemotherapy. Journal of Medicinal Chemistry 59, 6595-6628(2016), doi:10.1021/acs.jmedchem.5b01461

[10] Hoffmann M, et al The novel coronavirus 2019 (2019-nCoV) uses the SARScoronavirus receptor ACE2 and the cellular protease TMPRSS2 for entry into target cells. https://www.biorxiv.org/content/10.1101/2020.01.31.929042v1

[11] Sanoski CA. Aliskiren: An oral direct renin inhibitor for the treatment of hypertension. Pharmacotherapy; 29: 193-212 (2009)

[12] Jean- Jacques Mourad and Bernard I. Levy ,Interaction between RAAS inhibitors and ACE2 in the context of COVID-19 https://doi.org/10.1038/s41569-020-0368-X

[13] Gresele P, Momi S, Falcinelli E. Anti-platelet therapy: phosphodiesterase inhibitors. Br J Clin Pharmacol; 420 72(4): 634-46 (2011).

[14] Tonew E, Indulen MK, Dzeguze DR. Antiviral action of dipyridamole and its derivatives against influenza virus A. Acta Virol; 26(3): 125-9.423(1982)

[15] Fata-Hartley CL, Palmenberg AC. Dipyridamole reversibly inhibits mengovirus RNA replication. $J$ Virol; 79(17): 11062-70(2005).

[16] Tenser RB, Gaydos A, Hay KA. Inhibition of herpes simplex virus reactivation by dipyridamole. Antimicrob Agents Chemother; 45(12): 3657-9.427 (2001).

[17] Szebeni J, Wahl SM, Popovic M, et al. Dipyridamole potentiates the inhibition by 3'-azido-3'-deoxythymidine and other dideoxynucleosides of human immunodeficiency 
virus replication in monocyte-macrophages. Proc Natl . CC-BY-NC-ND 4.0 International license It is made available under a is the author/funder, who has granted medRxiv a license to display the preprint in perpetuity. (which was not peerreviewed)The copyright holder for this preprint . https://doi.org/10.1101/2020.02.27.20027557doi: medRxiv preprint

[18] Emmons PR, Harrison MJG, Honour AJ and Mitchell JRA, Effect of dipyridamole on human platelet behavior. Lancer ii: 603-606 (1965).

[19] Bunag RD, Douglas CR, Imai S and Berne RN, Influence of a pyrimidopyrimidine derivative on the amination of adenosine bv blood. Circ Res 15: 83-87, (1964).

[20] De La Cruz JP, Moron D and Sanchez de la Cuesta F. Antiplatelet effect of the pvrimido-pvrimidinic derivat\&e RA-642. Thromb Res kj: 463-4\&b, (1991).

[21] Watanabe M, Koike H, Ishiba T, Okada T, Seo 5, Hirai K: Synthesis and biological activity of methanesulfonamide pyrimidine- and N-methanesulfonyl pvrrole-substituted 3,5-dihydroxy-6 heptenoates, a novel seriers of HMGCo reductase iil-iihitoinhibitorsrs. Bioor Med Chem; 5:437-444(1997).

[22] Frost FJ, Petersen H, Tollestrup K, Skipper B. Influenza and COPD mortality protection as pleiotropic, dose-dependent effects of statins. Chest.;131(4):100612(2007).

[23] Shimada SG, Ottern ess IG, Stitt JT A study of the mechanism of action of the mild analgesic dipyrone. Agents Actions; 41: 188-192(1994).

[24] Liu F, Myres AG.. Development of a platform for the discovery and practical synthesis of new tetracycline antibiotics. Curr. Opin. Chem. Biol. 32: 48-57(2016).

[25] Chopra I, Hawkey P M, Hinton M. Tetracyclines, molecular and clinical aspects. J Antimicrob Chemother. ;29:245-277(1992).

[26] C. L. Tremblay, “Combating HIV resistance - Focus on darunavir,” Therapeutics and Clinical Risk Management, vol. 4, no. 4, pp. 759-765, (2008).

[27] K. McKeage, C. M. Perry, and S. J. Keam, "Darunavir: A Review of itsUse in the Management of HIV Infection in Adults,” Drugs, vol. 69, no. 4, pp. 477-503, (2009).

[28] E. Lefebvre and C. A. Schiffer, "Resilience to resistance of HIV-1 protease inhibitors: Profile of darunavir,” AIDS Reviews, vol. 10, no. 3, pp. 131-142, (2008). 
[30] Xiaoyan Liu, et al, Therapeutic effects of dipyridamole on COVID-19 patients with coagulation dysfunction medRxiv preprint doi: https://doi.org/10.1101/2020.02.27.20027557 